\title{
Comparative assessment of ecotoxicity of urban aerosol
}

\author{
B. Turóczi ${ }^{1}$, A. Hoffer ${ }^{2}$, Á. Tóth ${ }^{1}$, N. Kováts ${ }^{1}$, A. Ács ${ }^{1}$, Á. Ferincz ${ }^{1}$, A. Kovács ${ }^{1}$, and A. Gelencsér ${ }^{1}$ \\ ${ }^{1}$ University of Pannonia, Institute of Environmental Sciences, Veszprém, Hungary \\ ${ }^{2}$ Air Chemistry Group of the Hungarian Academy of Sciences, Veszprém, Hungary \\ Correspondence to: B. Turóczi (turoczi.beatrix @indamail.hu)
}

Received: 13 January 2012 - Published in Atmos. Chem. Phys. Discuss.: 2 April 2012

Revised: 23 July 2012 - Accepted: 24 July 2012 - Published: 16 August 2012

\begin{abstract}
In addition to its mass concentration, the health effects of urban particulate matter may depend on its particle size distribution and chemical composition. Yet air pollution regulations rely on exclusively bulk $\mathrm{PM}_{10}$ concentration measurements, without regard to their potentially different health effects under different conditions. Aerosols from various sources are well known to contain a plethora of toxic, carcinogenic, mutagenic or teratogenic constituents such as heavy metals and polycyclic aromatic hydrocarbons. Extensive public health studies established the link between mass concentrations of $\mathrm{PM}_{2.5} / \mathrm{PM}_{10}$ and health problems within the population. However, little is known about the relative importance of PM from different sources and the effect of seasonality on the toxicity. Here we present the application of a simple and sensitive method for the direct assessment of the overall ecotoxicity of various $\mathrm{PM}_{2.5} / \mathrm{PM}_{10}$ samples collected on filters. The method is based on the Vibrio fischeri bioluminescence inhibition bioassay that has been standardized for solid samples, representing a relevant biological exposure route. Direct emission samples proved to be significantly more ecotoxic than photochemically processed aerosol, thus marked differences were observed between the ecotoxicities of urban $\mathrm{PM}_{10}$ in summer and winter. These effects of urban $\mathrm{PM}_{10}$ may be useful supplementary indicators besides the mass concentrations of $\mathrm{PM}_{2.5} / \mathrm{PM}_{10}$ in cities.
\end{abstract}

\section{Introduction}

The health hazard posed by urban air pollution is evaluated and regulated on the basis of time-weighted average concentrations of criteria pollutants (e.g. $\mathrm{NO}_{\mathrm{x}}, \mathrm{CO}, \mathrm{O}_{3}, \mathrm{SO}_{2}$ and $\left.\mathrm{PM}_{2.5} / \mathrm{PM}_{10}\right)$. The latter is now identified as one of the most dangerous pollutants on human health by the EU new directive on air quality (2008/50/CE). In cities the sources of particulate matter are manifold, and the relative contributions of potential sources have been studied extensively (Schauer et al., 2006). Traffic-related sources such as vehicular exhaust, brake- or tire wear are important and more or less constant throughout the year whereas the intensities of other sources such as wood combustion are strongly seasonal. Emission from specific sources, for example road dust resuspension have strong dependence on meteorological factors. Atmospheric transport and photochemical transformations are also massively dependent on meteorology, yielding secondary aerosols which become the predominant component of urban particulate matter during summer.

The specific hazard associated with urban particulate matter is generally linked to the presence of toxic metals and hundreds of carcinogenic, mutagenic or toxic organic compounds such as polycyclic aromatic hydrocarbons (PAHs) or organic nitrates (Kelly and Fussel, 2012). In addition to in vivo acute toxicological tests, several in vitro bioassays have been developed and applied to explain the mechanisms of adverse effects caused by particulate matter. The dithiothreitol (DTT) assay is widely used to asses PM redox activity, utilizing the reduction of oxygen by dithiothreitol (Cho et al., 2005; DeVizcaya-Ruiz et al., 2006; Geller et al., 2006; Montiel-Dávalos et al., 2010; Verma et al., 2011). The formation of reactive oxygen species (ROS) is hypothesised to initiate oxidative stress in affected cells which in turn is associated with the development of many adverse health effects. Although oxidative stress might explain not only adverse health but also adverse ecological effects, there has been little effort to carry out ecotoxicological tests to assess the risk posed by PM on non-human biota. One possible reason could be that normally very low amount of PM can be collected (which in many cases limits the evaluation 
of PM toxicity as argued by DeVizcaya-Ruiz et al., 2006). Different mass contributions from various sources and different rates of atmospheric transformations yield markedly different chemical compositions of $\mathrm{PM}_{2.5} / \mathrm{PM}_{10}$. In spite of this fact, $\mathrm{PM}_{2.5} / \mathrm{PM}_{10}$ is treated in exactly the same way as any other criteria pollutant, i.e. as if it were single chemical species.

Extensive public health studies that establish the link between mass concentrations of $\mathrm{PM}_{2.5} / \mathrm{PM}_{10}$ and health problems within the population can be found in the literature (Pope and Dockery, 2006 and references therein). However, little is known about the relative importance of PM from different sources and the effect of seasonality on the toxicity. Due to the complexity of the $\mathrm{PM}_{2.5} / \mathrm{PM}_{10}$ chemical composition and the very low quantities available, direct measurements of the hazard posed by the particles are only sparsely available (Steenhof et al., 2011; Soto et al., 2008).

Ecotoxicity assays involving test microorganisms have long been routinely applied for surface and wastewaters for the assessment of their ecological and potential health hazard (Lin and Chao, 2002). The most frequently applied bacterial bioassay uses Vibrio fischeri, marine, bioluminescent bacteria (Vouitsis et al., 2009). The light output of luminescent microorganisms which emit light as a normal consequence of respiration is read by a luminometer. Chemicals or chemical mixtures, which are toxic to the bacteria, cause changes in some cellular structures or functions such as the electron transport system, cytoplasmic constituents or the cell membrane, resulting in a reduction in light output proportional to the strength of the toxin. As bioluminescence is directly linked to respiratory activity, it gives a good indication on the metabolic activity of the organism. It has been found to show good correlation with in vivo tests on higher organisms (Fort, 1992). Bioluminescence inhibition bioassays were successfully deployed for the assessment of potential health effects of organic extracts of particulate matter collected from vehicular exhaust (Lin and Chao, 2002; Isidori et al., 2003; Papadimitriou et al., 2008; Vouitsis et al., 2009). However, these studies only assess the ecotoxicity of a subfraction of $\mathrm{PM}_{2.5} / \mathrm{PM}_{10}$, and the deployment of organic solvents such as dimethyl-sulphoxide (DMSO) or dichloromethane, combined with Soxhlet extraction does not represent a realistic environmental exposure route.

Very recently we have developed a simple method for the direct assessment of the overall ecotoxicity of $\mathrm{PM}_{2.5} / \mathrm{PM}_{10}$ (Kováts et al., 2012). This method is based on the kinetic version of the Vibrio fischeri bioluminescence inhibition bioassay (Lappalainen et al., 1999) that has recently been standardized for the assessment of coloured suspensions such as sludge or sediment (ISO 21338:2010: Water quality - Kinetic determination of the inhibitory effects of sediment, other solids and coloured samples on the light emission of Vibrio fischeri /kinetic luminescent bacteria test/). Contrary to previous other measurements, the bulk samples are assayed without prior extraction, and no organic solvents are applied.
The objective of this paper is to present the application of this direct ecotoxicity test for aerosol samples of various origin, ranging from emission samples to ambient, from samples taken in photochemical smog to those collected during high pollution episodes in winter. In addition, based on the results of these measurements a comparison of ecotoxicities of various aerosol types is presented.

\section{Methodology}

\subsection{Sample collection}

Aerosols of various types (in Table 1) were sampled on quartz fiber filters. Urban $\mathrm{PM}_{10}$ samples were collected on 24-h basis with MSP personal $\mathrm{PM}_{10}$ sampler at a flow rate of $101 \mathrm{~min}^{-1}$ near a FAG FH $62 \mathrm{I}-\mathrm{N} \beta$-gauge dust monitor at the Main Observatory of the Hungarian Meteorological Service in Budapest. Samples were taken between 29 July-14 August 2009 and 20 January-12 February 2010. 18 summer and 24 winter $\mathrm{PM}_{10}$ samples were selected from these sampling periods for analyses.

Aerosol samples from the exhausts of 11 passenger cars with diesel engines and 6 buses of different engine types were collected with a KÁLMÁN PM 2.5 sampler at a flow rate of $32 \mathrm{~m}^{3} \mathrm{~h}^{-1}$ for $10 \mathrm{~min}$ at idling in a closed premise about $1 \mathrm{~m}$ from the tailpipes.

Cigarette smoke and biomass smoke were sampled with an MSP personal $\mathrm{PM}_{10}$ sampler at a flow rate of $101 \mathrm{~min}^{-1}$. Cigarette smoke samples were collected in a closed premise for $30 \mathrm{~min}$. Biomass smoke samples were collected for 30 min downwind from an open fireplace while burning small pieces of softwoods and hardwoods. Sampling times in all cases were selected to provide filter loads of about the same magnitude.

Resuspended road dust samples were collected with a special $\mathrm{PM}_{10}$ sampling unit including a PARTISOL FRM2000 aerosol sampler operating at a flow rate of $16.71 \mathrm{~min}^{-1}$ (Turóczi et al., 2012; Gelencsér et al., 2011). A rectangular stainless-steel hood was fixed to the front of a laboratory cart $0.5 \mathrm{~cm}$ above the road surface. A leaf blower was connected to the hood through two facing nozzles via a split flexible hose to induce turbulence inside the hood. The hood was connected to an alumina housing containing the R\&P $\mathrm{PM}_{10}$ inlet. A PARTISOL-FRM MODEL 2000 sampler collected resuspended $\mathrm{PM}_{1-10}$ samples in a cyclone separator and $\mathrm{PM}_{1}$ samples on filters. The sampling unit was powered with a portable electrical power generator, also mounted on the platform. The sampling times were $2 \mathrm{~h}$. In the case of emission samples both the conditions of sampling and the short sampling times ensure that the contribution of ambient $\mathrm{PM}$ is practically negligible. 
Table 1. Number of aerosol samples of various origins.

\begin{tabular}{llr}
\hline Aerosol types & Size range & $n$ \\
\hline Urban aerosol (winter) & $\mathrm{PM}_{10}$ & 24 \\
Urban aerosol (summer) & $\mathrm{PM}_{10}$ & 18 \\
Diesel emission aerosol (LDV) & $\mathrm{PM}_{2.5}$ & 11 \\
Diesel emission aerosol (bus) & $\mathrm{PM}_{2.5}$ & 6 \\
Cigarette smoke & $\mathrm{PM}_{10}$ & 8 \\
Biomass smoke & $\mathrm{PM}_{10}$ & 5 \\
Resuspended road dust & $\mathrm{PM}_{1-10}$ & 3 \\
\hline
\end{tabular}

\subsection{Ecotoxicity testing}

Ecotoxicological tests are controlled, reproducible tests where ecological responses are determined quantitatively, most often as $\mathrm{EC}_{50}$, that is the effective concentration causing $50 \%$ of effect. These tests cannot only provide quantitative information on the (eco)toxic effect, but a clear concentration-response relationship can be established and concentration-response or stressor-response patterns can be evaluated.

Since aerosol samples are collected on filters and ecotoxicity is to be measured in aqueous suspensions, a novel sample preparation protocol was developed (Kováts et al., 2012). $2 \mathrm{mg}$ of resuspended road dust samples were weighted with a microbalance ( $10 \mu \mathrm{g}$ sensitivity) into $4 \mathrm{ml}$ pre-weighted vials. From the filter samples spots of $25 \mathrm{~mm}$ in diameter were cut with a special puncher and ground in an agate mortar then transferred to vials, because the aerosol masses on filter spots were approximately $2 \mathrm{mg} .2 \mathrm{ml}$ of high-purity water was added to each vial and suspension was prepared by continuous stirring.

The aqueous suspensions were measured with Thermo Luminoscan Ascent unit. Ecotoxicity ( $\mathrm{EC}_{50}$ values) of samples were calculated using Ascent Software provided by Aboatox Co. The blank filters showed no ecotoxicity.

Ecotoxicity $\left(\mathrm{EC}_{50}\right)$ of a sample was determined as the absolute mass of aerosol particles that causes $50 \%$ reduction in the bioluminescence output of the test organisms relative to the control under the given experimental conditions. Therefore $\mathrm{EC}_{50}$ is expressed in units of $\mathrm{mg}$ as calculated from measured mass of aerosol on the total filter by scaling to the area of the sample spot. The lower the value of $\mathrm{EC}_{50}$ is, the higher the ecotoxicity of the sample.

\subsection{Determination of mass concentrations of total aerosols, levoglucosan and $\mathrm{NO}_{\mathrm{x}}$}

The mass concentrations of the summer and winter urban $\mathrm{PM}_{10}$ samples were determined directly by the FAG FH 62 I$\mathrm{N} \beta$-gauge dust monitor. According to the weekly standard comparisons done by the monitoring authorities the difference between the $\mathrm{PM}_{10}$ measured by $\beta$-gauge dust monitor and that measured gravimetrically at RH $50 \%$ is less than
$5 \%$. The $\mathrm{PM}_{10}$ mass of cigarette smoke, biomass smoke and resuspended road dust samples were determined by gravimetrically with a microbalance ( $10 \mu \mathrm{g}$ sensitivity). The $\mathrm{PM}_{2.5}$ mass concentrations of diesel engine exhaust samples were determined indirectly by total carbon (TC) mass measurements. In recent studies the $\mathrm{TC} / \mathrm{PM}_{2.5}$ ratio is 0.92 for passenger cars (Graham, 2005) and 0.85 for HDVs (Matti Maricq, 2007; Lowenthal et al., 1994). The total carbon concentrations were quantified with Zellweger Astro TOC 2100 total carbon analyzer.

The mass concentrations of levoglucosan (LGS) as a tracer for biomass burning were determined after silylation by gas chromatography-mass spectrometry (GC-MS) (Medeiros and Simoneit, 2007). For winter $\mathrm{PM}_{10}$ samples the $\mathrm{NO}_{\mathrm{x}}$ mass concentration data and meteorological parameters were provided by the Hungarian Meteorological Service for the same sampling site.

\section{Results and discussion}

$\mathrm{EC}_{50}$ values of various aerosol types are compared in Fig. 1. Mean values and ranges at $95 \%$ probability level of ecotoxicity are shown on the bars. Note that since $\mathrm{EC}_{50}$ values are measured with the same experimental setup and expressed as mass of aerosol, they are specific quantities which are independent of the filter loads.

In general, emission samples proved to be the most ecotoxic among all aerosol types tested. Fresh biomass smoke and cigarette smoke were of about the same level of ecotoxicity. Perhaps surprisingly, most diesel engine emission samples had higher $\mathrm{EC}_{50}$ values (thus lower ecotoxicities) than biomass smoke samples. While this finding warrants further studies it is worthy of note that by using a different toxicological approach Klippel and Nussbaumer (2007) also found that particles emitted by incomplete biomass burning showed higher toxicity than diesel soot. Diesel emission samples of passenger cars showed more scatter in measured $\mathrm{EC}_{50}$ values possibly due to different engine types, conditions and/or fuel qualities. Among the diesel engine emission samples of buses the $\mathrm{EC}_{50}$ values showed very high correlation with engine standards: ecotoxicity of EURO 0 and 1 engines were found to be the highest and that of EURO 4 engine was not to be detected. Given that the average particulate emission factor from a typical EURO 1 engine is in the range of $0.4 \mathrm{~g} \mathrm{~kW} \mathrm{~h}^{-1}$, whereas the limit for an EURO 4 engine is $0.02 \mathrm{~g} \mathrm{~kW} \mathrm{~h}^{-1}$, the reduction of potential acute health effects when replacing EURO 1 engines with EURO 4 ones is huge! These findings clearly justify the efforts of the European Commission to introduce stricter vehicle emission standards. Resuspended road dust as an aerosol source type, proved to be by far the least ecotoxic due to high fraction of inert mineral phases (Turóczi et al., 2012).

Among the ambient aerosol samples, urban $\mathrm{PM}_{10}$ collected in winter and summer showed markedly different 


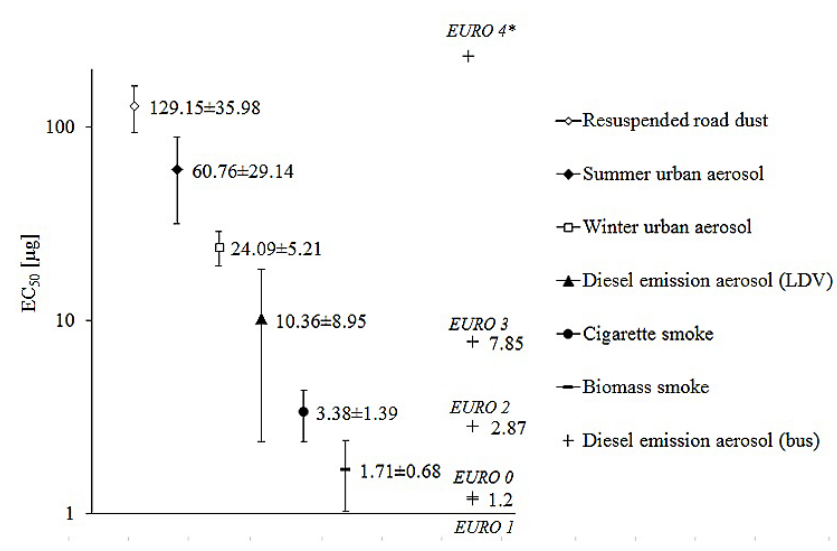

Fig. 1. Comparison of $\mathrm{EC}_{50}$ values of aerosols of various types. Note that the lower the $\mathrm{EC}_{50}$ value, the higher the ecotoxicity of the sample is. ${ }^{*}$ The diesel emission of EURO 4 engine was not ecotoxic.

ecotoxicities, with practically no overlap between the ranges of their $\mathrm{EC}_{50}$ values. Winter $\mathrm{PM}_{10}$ showed significantly higher ecotoxicity than summer $\mathrm{PM}_{10}$, even exceeding the ecotoxicity of EURO 4 diesel engine emissions! The low $\mathrm{EC}_{50}$ values of winter $\mathrm{PM}_{10}$ in Budapest follow from the high contribution of vehicular emissions from a rather aged vehicle fleet (average ages of LDVs and HDVs were 10 and $12 \mathrm{yr}$ in 2010 , respectively) as well as from the similarly high share of wood burning emissions which are also ecotoxic (Gelencsér et al., 2007). On the contrary, in summer the major source contributor to carbonaceous fraction of the $\mathrm{PM}_{2.5}$ in the region is secondary organic aerosol (SOA) from predominantly biogenic precursors (Gelencsér et al., 2007). A comprehensive recent study on $\mathrm{PM}_{10}$ chemistry in Europe showed that the mass contributions of inorganic salts to total $\mathrm{PM}_{10}$ vary quite little between the different seasons (Putaud et al., 2010). As the highly ecotoxic fresh biomass burning aerosol of winter $\mathrm{PM}_{10} / \mathrm{PM}_{2.5}$ is substituted with SOA in summer, a potential reduction of ecotoxicity may be expected. Due to the higher temperatures in summer there is significantly less condensation of semi-volatile organic compounds many of which are known to be highly ecotoxic (Reid et al., 1998; Verma et al., 2011). Furthermore, the significantly higher degree of atmospheric mixing in summer reduces the relative share of primary emission particulates and increases the contribution of atmospheric transport. Bioaerosol particles of probably negligible ecotoxicity are also more abundant in summer than in winter. Under dry conditions in summer the contribution of resuspended dust (which is largely inert and has very low specific ecotoxicity) to $\mathrm{PM}_{10}$ can be quite significant. Overall, the combination of these reinforcing factors may account for the significantly higher $\mathrm{EC}_{50}$ values (lower ecotoxicities) found in summer $\mathrm{PM}_{10}$ relative to those in winter.

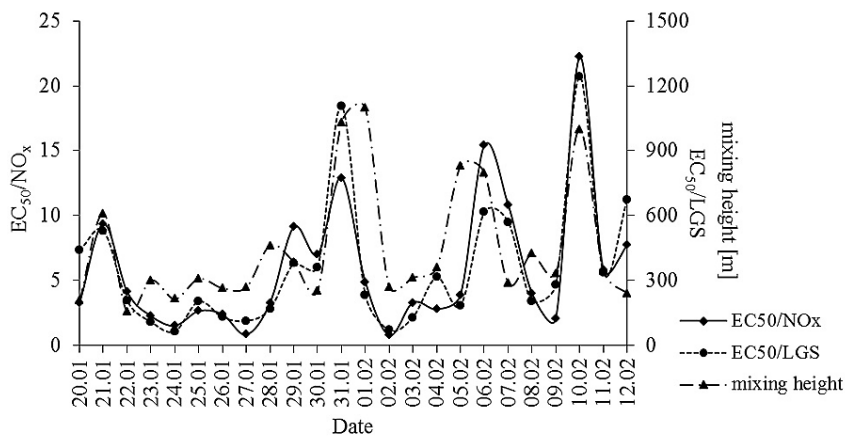

Fig. 2. Time series of the ratios of $\mathrm{EC}_{50} / \mathrm{LGS}\left[\mathrm{mg} \mathrm{m}^{3} \mu \mathrm{g}^{-1}\right.$ ] and $\mathrm{EC}_{50} / \mathrm{NO}_{\mathrm{x}}\left[\mathrm{mg} \mathrm{m}^{3} \mu \mathrm{g}^{-1}\right]$ in winter urban $\mathrm{PM}_{10}$ in the period between 20 January and 12 February 2010. The mixing heights are daily average values.

Figure 2 shows the ratios of $\mathrm{EC}_{50} / \mathrm{LGS}$ and $\mathrm{EC}_{50} / \mathrm{NO}_{\mathrm{x}}$ in the winter urban $\mathrm{PM}_{10}$ which varied substantially as a function of local meteorological conditions and the level of primary pollution.

The $\mathrm{EC}_{50} / \mathrm{NO}_{\mathrm{x}}$ and $\mathrm{EC}_{50} / \mathrm{LGS}$ ratios changed quite similarly during this period and their variations largely followed that of the mixing height. These findings imply that during high pollution episodes the relative mass contribution of locally emitted primary particulates increased at the expense of particles from atmospheric transport and other sources resulting in higher ecotoxicities compared to the low pollution case. In other terms, during high pollution episodes (smog alerts) not only the mass concentrations of $\mathrm{PM}_{10}$ are higher but the particles are significantly more ecotoxic on a per mass basis (up to a factor of 10) than during low pollution episodes! This highly unfavourable effect is implicitly reflected in air quality standards on $\mathrm{PM}_{10} / \mathrm{PM}_{2.5}$ mass concentrations.

\section{Conclusions}

Ecotoxicities of bulk $\mathrm{PM}_{10} / \mathrm{PM}_{2.5}$ of various types were directly measured by a novel ecotoxicity test. The results were not surprising in the sense that emission samples were generally more ecotoxic than ambient ones. However, wood smoke was found to be more ecotoxic than particulates emitted from modern diesel engines. This finding is unexpected and warrants further studies which might have an impact on future air quality legislation. The vast difference between the ecotoxicities of EURO 4 and EURO 1 diesel engines of buses combined with the similarly large differences between their particulate emissions - underlines the importance of speeding up the introduction of tighter emission standards. It follows from the higher ecotoxicity of primary emission that urban $\mathrm{PM}_{10}$ proved to more ecotoxic in winter than in summer due to the vast difference in aerosol sources and the degree of atmospheric mixing. An alarming conclusion of the 
present study is that in winter urban $\mathrm{PM}_{10} / \mathrm{PM}_{2.5}$ has significantly higher specific ecotoxicity during high pollution episodes than in times of low pollution levels. These results refer to the ecotoxicity of the particulates only and definitely not to their potential acute or chronic (carcinogenic, mutagenic, teratogenic etc.) effects on humans.

Acknowledgements. The authors are grateful for the financial support of the grants of the Hungarian Research Fund OTKA K 101484 and of TAMOP-4.2.1/B-09/1/KONV-2010-0003: Mobility and Environment: Researches in the fields of motor vehicle industry, energetics and environment in the Middle- and West-Transdanubian Regions of Hungary. The Project is supported by the European Union and co-financed by the European Regional Development Fund.

Edited by: B. Ervens

\section{References}

Cho, A. K., Sioutas, C., Miguel, A. H., Kumagai, Y., Schmitz, D. A., Singh, M., Eiguren-Fernandez, A., and Froines, J. R.: Redox activity of airborne particulate matter at different sites in the Los Angeles Basin, Environ. Res., 99, 40-47, 2005.

DeVizcaya-Ruiz, A., Gutiérrez-Castillo, M. E., Uribe-Ramirez, M., Cebrián, M. E., Mugica-Alvarez, V., Sepulvéda, J., Rosas, I., Salinas, E., Garcia-Cuéllar, C., Martínez, F., Alfaro-Moreno, E., Torres-Flores, V., Osornio-Vargas, A., Sioutas, C., Fine, P. M., Singh, M., Geller, M. D., Kuhn, T., Miguel, A. H., EigurenFernandez, A., Schiestl, R. H., Reliene, R., and Froines, J.: Characterization and in vitro biological effects of concentrated particulate matter from Mexico City, Atmos. Environ., 40, S583-S592, 2006.

Fort, F.: Correlation of Microtox EC, with mouse LD, Toxicol. in Vitro, 5, 73-82, 1992.

Gelencsér, A., May, B., Simpson, D., Sánchez-Ochoa, A., Kasper-Giebl, A., Puxbaum, H., Caseiro, A., Pio, C., and Legrand, M.: Source apportionment of $\mathrm{PM}_{2.5}$ organic aerosol over Europe: Primary/secondary, natural/anthropogenic, and fossil/biogenic origin, J. Geophys. Res., 112, D23S04, doi:10.1029/2006JD008094, 2007.

Gelencsér, A., Kováts, N., Turóczi, B., Rostási, Á., Hoffer, A., Imre, K., Nyirõ-Kósa, I., Csákberényi-Malasics, D., Tóth, Á., Czitrovszky, A., Nagy, A., Nagy, Sz., Ács, A., Kovács, A., Ferincz, Á., Hartyáni, Zs., and Pósfai, M.: The red mud accident in Ajka (Hungary): Characterization and potential health effects of fugitive dust, Environ. Sci. Technol., 45, 1608-1615, 2011.

Geller, M. D., Ntziachristos, L., Mamakos, A., Samaras, Z., Schmitz, D. A., Froines, J. R., and Sioutas, C.: Physicochemical and redox characteristics of particulate matter (PM) emitted from gasoline and diesel passenger cars, Atmos. Environ., 40, 6988-7004, 2006.

Graham, L.: Chemical characterization of emissions from advanced technology light-duty vehicles, Atmos. Environ., 39, 2385-2398, 2005.

Isidori, M., Ferrara, M., Lavorgna, M., Nardelli, A., and Parrella, A.: In situ monitoring of urban air in Southern Italy with the tradescantia micronucleus bioassay and semipermeable membrane devices (SPMDs), Chemosphere, 52, 121-126, 2003.

Kelly, F. J. and Fussell, J. C.: Size, Source and Chemical Composition as Determinants of Toxicity Attributable to Ambient Particulate Matter, Atmos. Environ., 60, 504-526, doi:10.1016/j.atmosenv.2012.06.039, 2012.

Klippel, N. and Nussbaumer, T.: Health relevance of particles from wood combustion in comparison to diesel soot, 15th European Biomass Conference and Exhibition, Berlin, 7-11 May, 2007.

Kováts, N., Ács, A., Kovács, A., Ferincz, Á., Turóczi, B., and Gelencsér, A.: Direct contact test for estimating the ecotoxicity of aerosol samples, Environ. Toxicol. Phar., 33, 223-228, 2012.

Lappalainen, J., Juvonen, R., Vaajasaari, K., and Karp, M.: A new flash method for measuring the toxicity of solid and colored samples, Chemosphere, 38, 1069-1083, 1999.

Lin, T. H. and Chao, M. R.: Assessing the influence of methanolcontaining additive on biological characteristics of diesel exhaust emissions using microtox and mutatox assays, Sci. Total Environ., 284, 61-74, 2002.

Lowenthal, D. H., Zielinska, B., Chow, J. C., Watson, J. G., Gautam, M., and Stevens, K. D.: Characterization of heavy-duty diesel vehicle emissions, Atmos. Environ., 28, 731-743, 1994.

Matti Maricq, M.: Chemical characterization of particulate emissions from diesel engines: A review, J. Aerosol Sci., 38, 10791118, 2007.

Medeiros, P. M. and Simoneit, B. R. T.: Analysis of sugars in environmental samples by gas chromatography-mass spectrometry, J. Chromatogr. A, 1141, 271-278, 2007.

Montiel-Dávalos, A., Ibarra-Sánchez, M. J., Ventura-Gallegos, J. L., Alfaro-Moreno, E., and López-Marure, R.: Oxidative stress and apoptosis are induced in human endothelial cells exposed to urban particulate matter, Toxicol. in Vitro, 24, 135-141, 2010.

Papadimitriou, C. A., Haritou, I., Samaras, P., and Zouboulis, A. I.: Evaluation of leaching and ecotoxicological properties of sewage sludge-fly ash mixtures, Environ. Res., 106, 340-348, 2008.

Pope, C. A. and Dockery, D. W.: Health effects of fine particulate air pollution: Lines that connect, J. Air Waste Manage., 56, 709742, 2006.

Putaud, J. P., Van Dingenen, R., Alastuey, A., Bauer, H., Birmili, W., Cyrys, J., Flentje, H., Fuzzi, S., Gehrig, R., Hansson, H. C., Harrison, R. M., Herrmann, H., Hitzenberger, R., Hüglin, C., Jones, A. M., Kasper-Giebl, A., Kiss, G., Kousa, A., Kuhlbusch, T. A. J., Löschau, G., Maenhaut, W., Molnar, A., Moreno, T., Pekkanen, J., Perrino, C., Pitz, M., Puxbaum, H., Querol, X., Rodriguez, S., Salma, I., Schwarz, J., Smolik, J., Schneider, J., Spindler, G., ten Brink, H., Tursic, J., Viana, M., Wiedensohler, A., and Raes, F.: A European Aerosol Phenomenology - 3: physical and chemical characteristics of particulate matter from 60 rural, urban, and kerbside sites across Europe, Atmos. Environ., 44, 1308-1320, 2010.

Reid, B. J., Semple, K. T., Macleod, C. J., Weitz , H. J., and Paton, G. I.: Feasibility of using prokaryote biosensors to assess acute toxicity of polycyclic aromatic hydrocarbons, FEMS Microbiol. Lett., 169, 227-233, 1998.

Schauer, J. J., Lough, G. C., Shafer, M. M., Christensen, W. F., Arndt, M. F., DeMinter, J. T., and Park, J. S.: Characterization of metals emitted from motor vehicles, Health Effect Institute, 2006. 
Soto, K. F., Garza, K. M., Shi, Y., and Murr, L. E.: Direct contact cytotoxicity assays for filter-collected, carbonaceous (soot) nanoparticulate material and observations of lung cell response, Atmos. Environ., 42, 1970-1982, 2008.

Steenhof, M., Gosens, I., Strak, M., Godri, K. J., Hoek, G., Cassee, F. R., Mudway, I. S., Kelly, F. J., Harrison, R. M., Lebret, E., Brunekreef, B., Janssen, N. AH., Pieters, R. HH.: In vitro toxicity of particulate matter $(\mathrm{PM})$ collected at different sites in the Netherlands is associated with PM composition, size fraction and oxidative potential - the RAPTES project, Part. Fibre Toxicol., 8, 26, doi:10.1186/1743-8977-8-26, 2011.

Turóczi, B., Hoffer, A., Nyírõ-Kósa, I., and Gelencsér, A.: Sampling and characterization of resuspended and respirable urban particulate matter, J. Air Waste Manage., in review, 2012.
Verma, V., Pakbin, P., Cheung, K. L., Cho, A. K., Schauer, J. J., Shafer, M. M., Kleinman, M. T., and Sioutas, C.: Physicochemical and oxidative characteristics of semi-volatile components of quasi-ultrafine particles in an urban atmosphere, Atmos. Environ., 45, 1025-1033, 2011.

Vouitsis, E., Ntziachristos, L., Pistikopoulos, P., Samaras, Z., Chrysikou, L., Samara, C., Papadimitriou, C., Samaras, P., and Sakellaropoulos, G.: An investigation on the physical, chemical and ecotoxicological characteristics of particulate matter emitted from light-duty vehicles, Environ. Pollut., 157, 2320-2327, 2009. 